Canadian Science Publishing

Applied Physiology, Nutrition, and Metabolism Physiologie appliquée, nutrition et métabolisme

\title{
Association between Maternal Dietary Inflammatory Index (DII) and Abortion in Iranian Women and Validation of DII with Serum Concentration of Inflammatory Factors: Case- Control Study
}

\begin{tabular}{|r|l|}
\hline Journal: & Applied Physiology, Nutrition, and Metabolism \\
\hline Manuscript ID & apnm-2016-0274.R2 \\
\hline Manuscript Type: & Article \\
\hline Date Submitted by the Author: & 17-Nov-2016 \\
\hline Complete List of Authors: & $\begin{array}{l}\text { Vahid, Farhad; Shaheed Beheshti University of Medical Sciences } \\
\text { Shivappa, Nitin; University of South Carolina; University of South Carolina } \\
\text { Hekmatdoost, Azita; Shaheed Beheshti University of Medical Sciences } \\
\text { Hebert, James; University of South Carolina } \\
\text { Davoodi, Sayed; Shaheed Beheshti University of Medical Sciences } \\
\text { Sadeghi, Mohammadreza ; Avicenna, Research Institute, }\end{array}$ \\
\hline Keyword: & $\begin{array}{l}\text { dietary analysis < nutrition, inflammation < inflammation, reproduction, } \\
\text { Dietary Inflammatory Index (DII), Abortion }\end{array}$ \\
\hline &
\end{tabular}

\section{SCHOLARONE \\ Manuscripts}


Association between Maternal Dietary Inflammatory Index (DII) and Abortion in Iranian Women and Validation of DII with Serum Concentration of Inflammatory Factors: Case-Control Study

$\underline{\text { Farhad Vahid }}^{1 *}$, Nitin Shivappa ${ }^{2,3}$, Azita Hekmatdoost ${ }^{4}$, James R Hebert ${ }^{2,}{ }^{3}$, Sayed Hossein Davoodi $^{4}$ Mohammadreza Sadeghi ${ }^{5}$

1*. Corresponding Author: Department of Nutritional Sciences, National Nutrition and Food Technology Research Institute, Faculty of Nutrition Sciences and Food Technology, Shahid Beheshti University of Medical Sciences, Tehran, Iran. Email: Farhang_3243@yahoo.com, Tel: +98-912-4443243; Fax +98-2122360657.

2. Cancer Prevention and Control Program, University of South Carolina, Columbia, SC 29208, USA

3. Department of Epidemiology and Biostatistics, Arnold School of Public Health, University of South Carolina, Columbia, SC 29208, USA

4. Departments of Clinical Nutrition and Dietetics, Faculty of Nutrition and Food Technology, National Nutrition and Food Technology Research Institute, Shahid Beheshti University of Medical Sciences, Tehran, Iran.

5. Department of Andrology and Embryology, Reproductive Biotechnology Research Center, Avicenna, Research Institute, ACECR, Tehran, Iran. 


\begin{abstract}
Background: Previous studies have shown that some dietary components may be implicated in the etiology of abortion. However, the possible relationship between diet-related inflammation and the risk of abortion has not yet been investigated.

Methods: We examined the ability of the literature-derived dietary inflammatory index (DII) to predict the abortion incidence in women suffering from recurrent abortion in a case-control study conducted from April 2010 to March 2011. This included 67 incident cases and 68 controls, frequency-matched to cases on age, who attended infertility and miscarriage specialized centers in Tehran, Iran. The DII was computed based on dietary intake assessed using a validated and reproducible 168 item FFQ. Logistic regression models were used to estimate multivariable ORs adjusted for age, education, occupation and BMI.

Results: Subjects with higher DII scores (i.e., a more pro-inflammatory diet) had higher odds of abortion, with the DII being used as a continuous variable $\left(\mathrm{OR}_{\text {continuous }}=2.12,95 \% \mathrm{CI}\right.$ : 1.02 4.43). When analysis was carried out with DII expressed as a dichotomous variable, women in the pro-inflammatory diet group (DII $>1.24$ ) were at 2.12 times higher odds of having abortion compared to women in the referent group $(\mathrm{DII} \leq 1.24)(\mathrm{ORDII}>1.24 / \leq 1.24=2.12$; $95 \% \mathrm{CI}$ : 1.02 4.43). In the same study, for every one-unit increase in DII, there was a corresponding increase in IL-6 by $0.15 \mathrm{pg} / \mathrm{ml}, 95 \% \mathrm{CI}(<0.01,0.28)$.

Conclusion: In conclusion, subjects who consumed a more pro-inflammatory diet were at increased odds of abortion compared to those who consumed a more anti-inflammatory diet. Keywords: Dietary analysis, inflammation, Reproduction, Dietary Inflammatory Index (DII), Abortion, Nutrition
\end{abstract}




\section{INTRODUCTION}

Although spontaneous abortion occurs in 40 to $50 \%$ of pregnancies, the causes, especially for recurrent abortions, are still unknown (Abir et al. 1994). Various definitions of spontaneous abortion exist among which the most common is disposal of the fetus before $20^{\text {th }}$ week after fertilization (Nelson et al. 2014). When spontaneous abortion occurs $\geq 3$ times consecutively; i.e., categorized as recurrent abortion, it is considered a pathologic situation, requiring more attention and appropriate treatment. Although prevalence of recurrent abortion is about $2 \%$ of all pregnancies (Kenneth 1995; Bulletti et al. 1996) it places a heavy psychological and financial burden on the families and healthcare system, is considered very big problem (Hekmatdoost et al. 2015). Many factors are considered in recurrent abortion etiology such as anatomic abnormalities, immunologic, endocrine and cytological disorders; and infection, inflammation, genetics and nutritional factors (Bulletti et al. 1996; Hill 1997; Scholl and Johnson 2000; Pfeiffer et al. 2001).

Inflammation is the result of body's respond to tissue-damages or other factors that produce proinflammatory stimuli (Keibel et al. 2009; Valin and Pablos 2015). The response of the immune system to tissue damage involves a carefully choreographed series of cellular interactions between immune and non-immune cells (Valin and Pablos 2015). Chronic inflammation occurs when the normal processes associated with negative feedback signaling are short circuited. Chronic inflammation is associated with a number of conditions including cancer, autoimmune diseases, diabetes and chronic diseases. Chronic inflammation and serum levels of C-reactive protein (CRP) has been shown to play a role in abortion in some studies (Romero et al. 2004; Deftereou et al. 2012; Cicinelli et al. 2014; Wang et al. 2014; Ahmed et al. 2015) and the inconsistency in results underlines that understanding the causes of spontaneous abortion is 
methodologically challenging. On the other hand, it is not clear that how much of an effect nutrition or natural changes during pregnancy affect delivery status.

There is considerable evidence that diet plays an important and central role in the regulating chronic inflammation (Esposito et al. 2006a; Esposito et al. 2006b; Esposito and Giugliano 2006; Giugliano et al. 2006). Special dietary compounds can influence inflammation (Galland 2010; Vahid et al. 2015), and these, in turn, may affect spontaneous abortion.

Western diet containing high concentrations of red meat, dairy products high in fat and simple carbohydrates; are associated with high levels of CRP and interleukin (IL)-6. By contrast, Mediterranean diet containing high amounts of whole grains, fish, fruit and green leafy vegetables and moderate amounts of alcohol and olive oil and low amounts of red meat and butter is associated with low levels of inflammation (Chrysohoou et al. 2004; Esposito et al. 2004; Serrano-Martinez et al. 2005; Dalziel et al. 2006; Estruch et al. 2006; Esmaillzadeh et al. 2007).

In a study conducted in North-West Iran, it was shown that pregnant Iranian women who live in rural areas have healthier nutritional status and dietary patterns compared with pregnant women who live in urban areas (Esmaillzadeh et al. 2008). This study also shows that those pregnant women who live in rural areas consume more fruit but there was no significant difference between fat and vegetables intake. There were low intakes of vitamin C, zinc, magnesium and vitamin A in pregnant women (Esmaillzadeh, Samareh et al. 2008).

Dietary Inflammatory Index (DII) is a dietary tool developed to measure the inflammatory potential of individual's diet (Cavicchia et al. 2009; Shivappa et al. 2014a). DII has been shown to be predictive of levels of various inflammatory markers (Cavicchia et al. 2009; Shivappa et al. 2014b; Shivappa et al. 2015b). DII can be used to evaluate the dietary inflammatory potential in 
different populations using a variety of assessment instruments such as 24-hour recall interviews, food frequency questionnaires (FFQ) and food record (Shivappa et al. 2014a; Shivappa et al. 2014b; Wirth et al. 2014; Wood et al. 2015).

In the current study, we examined the relationship between DII scores and abortion in women suffering from recurrent abortion. We also assessed the association between DII scores and serum concentrations of inflammatory markers in an Iranian case-control study. Our hypothesis is that a higher DII score (indicating a pro-inflammatory diet) is associated with increases odds of abortion and higher levels of inflammation.

\section{METHODS}

\section{Participants}

Cases and controls were selected from among women with recurrent miscarriage issues who attended infertility and miscarriage specialized centers in Tehran, Iran. A total of 135 women (20-45 years old) who had a history of 3 or more times of miscarriage were recruited for the study. Sixty-seven women, who had an abortion before the $20^{\text {th }}$ week during study period, were cases and 68 pregnant women still pregnant until the $20^{\text {th }}$ week served as controls. Data collection lasted from April 2010 to March 2011. Cases and controls were frequency matched by age ( \pm 5 years). Protocols and procedures of this study were approved by the Ethics Board of the National Nutrition and Food Technology Research Institute, Iran, and all participants provided written consents after being informed of the purpose of this research, indicating their willingness to participate. 


\section{Inclusion and exclusion criteria}

Recurrent abortion was defined as $\geq 3$ consecutive miscarriage. Inclusion criteria in the case group included idiopathic abortion (unknown etiology) before the $20^{\text {th }}$ week of pregnancy, maximum of 6 months had elapsed since the last abortion, did not receive supplements containing folic acid in the last 6 months. Exclusion criteria were: ectopic pregnancy; intentional or elective abortions and/or those whose abortion had an anatomic, immunological, cytological, hormonal or infectious etiology; active malignant disease or chromosomal abnormalities; impaired renal, hepatic, endocrine, immune or gastrointestinal functions and drinking alcohol; smoking or drugs abuse. Inclusion criteria for control group included the following: being pregnant for $>20$ weeks; the absence of abortion in the last 6 months; and has not received supplements containing folic acid in the last 6 months and exclusion criteria were, presence of active cancer or chromosomal abnormalities; impaired renal, hepatic, endocrine, immune or gastrointestinal functions; and drinking alcohol, smoking or drug abuse.

\section{Assessment of other variables}

Information on age, education level, number of previous abortions, number of previous pregnancies, and participant's status at baseline were obtained from general information questionnaire which was filled out while interviewing the participants, and from reviewing medical records. Weight and height measurements at baseline were measured and body mass index $(\mathrm{BMI})$ was calculated by dividing the patient's weight $(\mathrm{kg})$ by the square of height $\left(\mathrm{m}^{2}\right)$. Confirmation of abortions, pregnancies and the number of weeks of pregnancy in all patients was performed with clinical manifestations, biochemical and ultrasound tests. Serum levels of 
inflammatory markers including CRP and IL-6 for all participants was measured using kits produced by Monobind Inc, provided by Negin Daroo Co.

\section{Assessment of dietary intake}

Food intake was ascertained from participants by interview with trained experts using a 168-item food frequency questionnaire (FFQ) (Esfahani et al. 2010). The information obtained through the questionnaire was analyzed using nutritional software Nutritionist 4 (First Databank, Hearst Corp, San Bruno, CA, USA).

\section{Assessment of DII}

FFQ-derived dietary data were used to calculate DII scores for all participants. The DII is based on literature published through 2010 linking diet to inflammation. Individuals' intakes of food parameters on which the DII is based are then compared to a world standard database. A complete description of the DII is available elsewhere (Shivappa et al. 2014a). A description of validation work, including DII derived from both dietary recalls and a structured questionnaire similar to an FFQ and related to interval values of hs-CRP, also is available (Shivappa et al. 2014a). Briefly, to calculate DII for the participants of this study, the dietary data were first linked to the regionally representative world database we constructed that provided a robust estimate of a mean and standard deviation for each parameter (Shivappa et al. 2014a). These then become the multipliers to express an individual's exposure relative to the "standard global mean" as a z-score. This is achieved by subtracting the "standard global mean" from the amount reported and dividing this value by the standard deviation. To minimize the effect of "right skewing" (a common occurrence with dietary data), this value is then converted to a centered percentile score. The centered percentile score for each food parameter for each individual was then multiplied by the respective food parameter effect score, which is derived from the literature 
review, in order to obtain a food parameter-specific DII score for an individual. All of the food parameter-specific DII scores are then summed to create the overall DII score for every participant in the study (Shivappa et al. 2014a). DII = b1*n1+b2*n2.........b31*n31, where b refers to the literature-derived inflammatory effects score for each of the evaluable food parameters and $\mathrm{n}$ refers to the food parameter-specific centered percentiles, which were derived from this case-control's dietary data. Of the theoretically possible list of 45 food parameters, a total of 31 were available from this FFQ and therefore could be used to calculate DII (energy, carbohydrate, protein, total fat, fiber, cholesterol, saturated fat, mono-unsaturated fat, poly unsaturated fat, omega-3, omega-6, niacin, thiamin, riboflavin, vitamin B12, vitamin B6, iron, magnesium, selenium, zinc, vitamin $\mathrm{A}$, vitamin $\mathrm{C}$, vitamin $\mathrm{D}$, vitamin $\mathrm{E}$, folic acid, beta carotene, garlic, ginger, onion, turmeric, saffron, pepper.)

With inflammatory markers as outcomes, DII was analyzed as a continuous exposure whereas when abortion was outcome DII was used as both continuous and as a dichotomous variable, categorized based on the median value of the DII for the controls (1.20). DII (as dichotomous) was examined across the following characteristics: age, body mass index (BMI), CRP, IL-6, education and occupation using $A N O V A$ or $\chi^{2}$ test for continuous and categorical variables, respectively. The inflammatory markers were log transformed. Beta estimates and 95\% confidence intervals for the inflammatory markers were estimated using linear regression and odds ratios and $95 \%$ confidence intervals for abortion as outcome were estimated using logistic regression models, adjusting only for age and then fitting a model with additional adjustment for sex, BMI, education and occupation. The covariates were chosen a priori. Statistical tests were performed using SAS $^{\circledR} 9.3$ (SAS Institute Inc., Cary, NC); all p values were based on two-sided tests. 


\section{RESULTS}

The DII scores in this study ranged from -0.50 (most anti-inflammatory score) to 2.70 (most proinflammatory score). Table 1 shows the distribution of 67 cases of abortion and 68 controls according to selected variables. Cases had higher DII score and IL-6 levels compared to controls. The mean DII value among cases was $1.51(\mathrm{SD}=0.63)$; among controls it was $1.22(\mathrm{SD}=0.63)$, indicating a more pro-inflammatory diet for cases.

Control characteristics by DII categories are provided in Table 2. In particular, participants in DII $>1.24$ category had higher BMI, were slightly older, and had lower education. However, the results were not significant except for BMI.

Beta estimates and 95\% confidence intervals for DII and inflammatory markers are shown in Table 3. For every one-unit increase in DII, there was a corresponding increase in IL-6 by 0.15 $\mathrm{pg} / \mathrm{ml}, 95 \% \mathrm{CI}(<0.01,0.28)$; no significant association was observed with CRP although the association was in the expected direction.

Odds ratios (OR) and 95\% confidence intervals (CI) for the abortion according to continuous and cut-points of DII are shown in Table 4. Results obtained from modeling DII as a continuous variable in relation to abortion showed a positive association after adjustment for age $(\mathrm{OR}=2.15$ $\mathrm{CI}=1.22-3.80)$ and in the multivariate analysis $(\mathrm{OR}=2.05, \mathrm{CI}=1.14-3.70)$. When analysis was carried out with DII expressed as a dichotomous variable, and adjusting for age, subjects with DII score $>1.24$ were at 2.26 times higher odds of having abortion compared to subjects with DII $\leq 1.24(\mathrm{ORDII}>1.24 / \leq 1.24=2.26 \mathrm{CI}=1.11-4.60)$. After multivariable adjustment, subjects with DII $>1.24$ were at 2.12 times higher odds of having abortion compared to subjects with $\mathrm{DII} \leq 1.24$ ORDII $>1.24 / \leq 1.24=2.12 ; \mathrm{CI}=1.02-4.43$. 


\section{DISCUSSION}

In this case-control study, designed to assess the relationship between inflammatory potential of diet assessed by the DII and abortion among Iranian women, we found that subjects with higher DII scores (i.e., indicating a pro-inflammatory diet) were at increased odds of having abortion, a result supporting our hypothesis that consuming a more pro-inflammatory diet, is associated with an increased abortion. We also observed a significant positive relationship between IL-6 and DII score such that for every one unit increase in DII there was a corresponding increase in IL-6 by $0.15 \mathrm{pg} / \mathrm{ml}$. This indicates that the DII can predict inflammatory markers in chronic inflammatory states. We found no association between DII and CRP, although there was a suggestion of a positive association.

This is the first report of the association between the DII and abortion among women suffering from recurrent abortion. This also is the first study to validate the DII with inflammatory markers in Iran. The use of the DII has several unique advantages over other dietary measures and was designed specifically in reference to inflammation (Shivappa et al. 2014a).

Previous studies have found that certain nutrients such as omega-3 fatty acids (Lopez-Garcia et al. 2004; Ferrucci et al. 2006); fiber (King et al. 2003; Bo et al. 2006); moderate consumption of wine and alcohol (Imhof et al. 2001; van Herpen-Broekmans et al. 2004); vitamin E (Devaraj and Jialal 2000; Murphy et al. 2004; Bertran et al. 2005); vitamin C (Bertran et al. 2005; Wannamethee et al. 2006), Beta-carotenes (Kritchevsky et al. 2000; van Herpen-Broekmans, et al. 2004; Bertran et al. 2005) and Magnesium (King et al. 2005; Bo et al. 2006) are associated with low levels of inflammation.

A limitation of this single-food/nutrient-based approach is that these foods or nutrients are usually consumed with other food items and nutrients; thus, dietary interactions may modify the 
actual effects of the food or nutrient under study. A high correlation between nutrients and among foods can produce instability in risk estimation due to multicollinearity. In turn, this can result in the loss of statistical power and distortion of risk estimates. In the formulation of the DII, an entirely different approach was taken by focusing on the functional effects of foods and nutrients. As such, the DII relies on reviewing and scoring of the peer-reviewed literature on the subject of diet and inflammation. Also, it standardizes individuals' dietary intakes of pro- and anti-inflammatory food constituents to world reference values, resulting in values that are not dependent on units of consumption and can be used for comparison across studies (Shivappa et al. 2014a).

One of the possible mechanisms for the positive association between the DII and abortion and other chronic inflammatory states might be through the effect of a pro-inflammatory diet on insulin resistance by increasing systemic inflammation (Festa et al. 2000). Some studies (Romero et al. 2004; Deftereou et al. 2012; Cicinelli et al. 2014; Wang et al. 2014; Ahmed et al. 2015) have noted chronic and systemic inflammation to play an important role in risk of abortion, but whence abortion etiology is multifactorial, this mechanism will not be held accountable for all abortions.

An important strength of this study is that it is the first one in Iran to examine abortion as an outcome. Another strength is the use of a validated and reproducible FFQ (Esfahani et al. 2010), which allowed for a comprehensive assessment of major nutrient sources in diet, although some measurement error inherent in the FFQ may be present. Also, controls were selected carefully by ensuring that none of them had any condition related to diet or other major risk factors of abortion. Previously, the DII was associated with lower bone mineral density in a study among post-menopausal Iranian women(Shivappa et al. 2015a). However, in addition to the strengths 
there are certain weaknesses of this study that need to be considered. First, random measurement error will lead to underestimation of results. Second, error in the measurement of confounders will lead to residual confounding (Fewell et al. 2007). Third, as with other case-control studies, recall bias and selection bias were inevitable. However, our participants were generally of low literacy and socioeconomic status, and likely to have little knowledge about the role of diet and nutrients in the abortion. This should have reduced the possibility of recall bias. Moreover, administering a validated FFQs by trained interviewers in a hospital setting might have further reduced the recall bias and improved comparability of information of cases and controls.

In conclusion, subjects who consumed a more pro-inflammatory diet were at increased odds of abortion compared to those who consumed a more anti-inflammatory diet. Thus, encouraging intake of more anti-inflammatory dietary factors, such as omega-3 fatty acids, plant-based foods rich in fiber, beta-carotenes and phytochemicals, and reducing intake of pro-inflammatory factors, such as fried foods or processed foods rich in saturated fat or trans fatty acids, may be a strategy for reducing risk of some cases of abortion. Future studies are needed to gain insight into the relationship between DII and abortion; this would deepen understanding about the role of diet and inflammation in abortion. Also future research should test whether changing the inflammatory potential of diet can reduce chronic inflammation and the risk of abortion. The utility of the DII can be extended to clinical settings to address inflammatory potency of one's diet, and possibly reduce future risk of chronic inflammatory-related diseases.

Funding: Drs Shivappa and Hebert were funded by grant R44DK103377 from the U.S. National Institute of Diabetes, Digestive and Kidney Diseases.

Disclosure: Dr. James R. Hébert owns controlling interest in Connecting Health Innovations LLC (CHI), a company planning to license the right to his invention of the dietary inflammatory 
index (DII) from the University of South Carolina in order to develop computer and smart phone applications for patient counseling and dietary intervention in clinical settings. Dr. Nitin Shivappa is an employee of CHI.

\section{References}

Abir, R., Ornoy, A., Ben Hur, H., Jaffe, P., andPinus, H. 1994. The effects of sera from women with spontaneous abortions on the in vitro development of early somite stage rat embryos. Am. J. Reprod. Immunol. 32: 73-81.

Ahmed, S.K., Mahmood, N., Malalla, Z.H., Alsobyani, F.M., Al-Kiyumi, I.S., andAlmawi, W.Y. 2015. Creactive protein gene variants associated with recurrent pregnancy loss independent of CRP serum levels: a case-control study. Gene. 569: 136-40.

Bertran, N., Camps, J., Fernandez-Ballart, J., Arija, V., Ferre, N., Tous, M., Simo, D., Murphy, M.M., Vilella, E., andJoven, J. 2005. Diet and lifestyle are associated with serum C-reactive protein concentrations in a population-based study. J. Lab. Clin. Med. 145: 41-6.

Bo, S., Durazzo, M., Guidi, S., Carello, M., Sacerdote, C., Silli, B., Rosato, R., Cassader, M., Gentile, L., andPagano, G. 2006. Dietary magnesium and fiber intakes and inflammatory and metabolic indicators in middle-aged subjects from a population-based cohort. Am. J. Clin. Nutr. 84: 1062-9.

Bulletti, C., Flamigni, C., andGiacomucci, E. 1996. Reproductive failure due to spontaneous abortion and recurrent miscarriage. Hum. Reprod. Update. 2: 118-36.

Cavicchia, P.P., Steck, S.E., Hurley, T.G., Hussey, J.R., Ma, Y., Ockene, I.S., andHebert, J.R. 2009. A new dietary inflammatory index predicts interval changes in serum high-sensitivity C-reactive protein. J. Nutr. 139: 2365-72.

Chrysohoou, C., Pitsavos, C., Panagiotakos, D.B., Skoumas, J., andStefanadis, C. 2004. Association between prehypertension status and inflammatory markers related to atherosclerotic disease: The ATTICA Study. Am. J. Hypertens. 17: 568-73. 
Cicinelli, E., Matteo, M., Tinelli, R., Pinto, V., Marinaccio, M., Indraccolo, U., De Ziegler, D., andResta, L. 2014. Chronic endometritis due to common bacteria is prevalent in women with recurrent miscarriage as confirmed by improved pregnancy outcome after antibiotic treatment. Reprod. Sci. 21: 640-7.

Dalziel, K., Segal, L., andde Lorgeril, M. 2006. A mediterranean diet is cost-effective in patients with previous myocardial infarction. J. Nutr. 136: 1879-85.

Deftereou, T.E., Lambropoulou, M., Chatzaki, E., Koffa, M., Ypsilantis, P., Pagonopoulou, O., Grammatikopoulou, I., Papadopoulos, E., Papalambros, A., Kontomanolis, E., andPapadopoulos, N. 2012. Increased apoptotic activity on inflammatory human placentas in spontaneous abortions during the first and second trimester of gestation: a histochemical and immunohistochemical study. Folia. Histochem. Cytobiol. 50: 118-24.

Devaraj, S. and Jialal, I. 2000. Alpha tocopherol supplementation decreases serum C-reactive protein and monocyte interleukin-6 levels in normal volunteers and type 2 diabetic patients. Free. Radic. Biol. Med. 29: 790-2.

Esfahani, F.H., Asghari, G., Mirmiran, P., andAzizi, F. 2010. Reproducibility and relative validity of food group intake in a food frequency questionnaire developed for the Tehran Lipid and Glucose Study. J. Epidemiol. 20: 150-8.

Esmaillzadeh, A., Kimiagar, M., Mehrabi, Y., Azadbakht, L., Hu, F.B., andWillett, W.C. 2007. Dietary patterns and markers of systemic inflammation among Iranian women. J. Nutr. 137: 992-8.

Esmaillzadeh, A., Samareh, S., andAzadbakht, L. 2008. Dietary patterns among pregnant women in the west-north of Iran. Pak. J. Biol. Sci. 11: 793-6.

Esposito, K., Ciotola, M., Carleo, D., Schisano, B., Saccomanno, F., Sasso, F.C., Cozzolino, D., Assaloni, R., Merante, D., Ceriello, A., andGiugliano, D. 2006a. Effect of rosiglitazone on endothelial function and inflammatory markers in patients with the metabolic syndrome. Diabetes. Care. 29: 1071-6. 
Esposito, K., Ciotola, M., andGiugliano, D. 2006b. Mediterranean diet, endothelial function and vascular inflammatory markers. Public. Health. Nutr. 9: 1073-6.

Esposito, K. and Giugliano, D. 2006. Whole-grain intake cools down inflammation. Am. J. Clin. Nutr. 83: 1440-1; author reply 1441-2.

Esposito, K., Marfella, R., Ciotola, M., Di Palo, C., Giugliano, F., Giugliano, G., D'Armiento, M., D'Andrea, F., andGiugliano, D. 2004. Effect of a mediterranean-style diet on endothelial dysfunction and markers of vascular inflammation in the metabolic syndrome: a randomized trial. JAMA. 292: 1440-6.

Estruch, R., Martinez-Gonzalez, M.A., Corella, D., Salas-Salvado, J., Ruiz-Gutierrez, V., Covas, M.I., Fiol, M., Gomez-Gracia, E., Lopez-Sabater, M.C., Vinyoles, E., Aros, F., Conde, M., Lahoz, C., Lapetra, J., Saez, G., Ros, E., andlnvestigators, P.S. 2006. Effects of a Mediterranean-style diet on cardiovascular risk factors: a randomized trial. Ann. Intern. Med. 145: 1-11.

Ferrucci, L., Cherubini, A., Bandinelli, S., Bartali, B., Corsi, A., Lauretani, F., Martin, A., Andres-Lacueva, C., Senin, U., andGuralnik, J.M. 2006. Relationship of plasma polyunsaturated fatty acids to circulating inflammatory markers. J. Clin. Endocrinol. Metab. 91: 439-46.

Festa, A., D'Agostino, R., Jr., Howard, G., Mykkanen, L., Tracy, R.P., andHaffner, S.M. 2000. Chronic subclinical inflammation as part of the insulin resistance syndrome: the Insulin Resistance Atherosclerosis Study (IRAS). Circulation. 102: 42-7.

Fewell, Z., Davey Smith, G., andSterne, J.A. 2007. The impact of residual and unmeasured confounding in epidemiologic studies: a simulation study. Am. J. Epidemiol. 166: 646-55.

Galland, L. 2010. Diet and inflammation. Nutr. Clin. Pract. 25: 634-40.

Giugliano, D., Ceriello, A., andEsposito, K. 2006. The effects of diet on inflammation: emphasis on the metabolic syndrome. J. Am. Coll. Cardiol. 48: 677-685.

Hekmatdoost, A., Vahid, F., Yari, Z., Sadeghi, M., Eini-Zinab, H., Lakpour, N., andArefi, S. 2015. Methyltetrahydrofolate vs Folic Acid Supplementation in Idiopathic Recurrent Miscarriage with Respect 
to Methylenetetrahydrofolate Reductase C677T and A1298C Polymorphisms: A Randomized Controlled Trial. PLoS. One. 10: e0143569.

Hill, J.A. 1997. Immunotherapy for recurrent pregnancy loss: "standard of care or buyer beware". J. Soc. Gynecol. Investig. 4: 267-73.

Imhof, A., Froehlich, M., Brenner, H., Boeing, H., Pepys, M.B., andKoenig, W. 2001. Effect of alcohol consumption on systemic markers of inflammation. Lancet. 357: 763-7.

Keibel, A., Singh, V., andSharma, M.C. 2009. Inflammation, microenvironment, and the immune system in cancer progression. Curr. Pharm. Des. 15: 1949-55.

Kenneth J.R MD, r.s.B., Babieri, R.L., and Kistner, R.W. 1995. Kistner's Gynecology. Principles and practice. 6: 330-365.

King, D.E., Egan, B.M., andGeesey, M.E. 2003. Relation of dietary fat and fiber to elevation of C-reactive protein. Am. J. Cardiol. 92: 1335-9.

King, D.E., Mainous, A.G., 3rd, Geesey, M.E., andWoolson, R.F. 2005. Dietary magnesium and C-reactive protein levels. J. Am. Coll. Nutr. 24: 166-71.

Kritchevsky, S.B., Bush, A.J., Pahor, M., andGross, M.D. 2000. Serum carotenoids and markers of inflammation in nonsmokers. Am. J. Epidemiol. 152: 1065-71.

Lopez-Garcia, E., Schulze, M.B., Manson, J.E., Meigs, J.B., Albert, C.M., Rifai, N., Willett, W.C., andHu, F.B. 2004. Consumption of (n-3) fatty acids is related to plasma biomarkers of inflammation and endothelial activation in women. J. Nutr. 134: 1806-11.

Murphy, R.T., Foley, J.B., Tome, M.T., Mulvihill, N.T., Murphy, A., McCarroll, N., Crean, P., andWalsh, M.J. 2004. Vitamin E modulation of C-reactive protein in smokers with acute coronary syndromes. Free. Radic. Biol. Med. 36: 959-65.

Nelson DB, Casey BM, McIntire DD, Cunningham FG. 2014. Subsequent pregnancy outcomes in women previously diagnosed with subclinical hypothyroidism. American journal of perinatology. 31(1):77-84. 
Pfeiffer, K.A., Fimmers, R., Engels, G., van der Ven, H., andvan der Ven, K. 2001. The HLA-G genotype is potentially associated with idiopathic recurrent spontaneous abortion. Mol. Hum. Reprod. 7: 373-8.

Romero, R., Espinoza, J., andMazor, M. 2004. Can endometrial infection/inflammation explain implantation failure, spontaneous abortion, and preterm birth after in vitro fertilization? Fertil. Steril. 82: 799-804.

Scholl, T.O. and Johnson, W.G. 2000. Folic acid: influence on the outcome of pregnancy. Am. J. Clin. Nutr. 71: 1295S-303S.

Serrano-Martinez, M., Palacios, M., Martinez-Losa, E., Lezaun, R., Maravi, C., Prado, M., Martinez, J.A., andMartinez-Gonzalez, M.A. 2005. A Mediterranean dietary style influences TNF-alpha and VCAM-1 coronary blood levels in unstable angina patients. Eur. J. Nutr. 44: 348-54.

Shivappa, N., Hebert, J.R., Karamati, M., Shariati-Bafghi, S.E., andRashidkhani, B. 2015a. Increased inflammatory potential of diet is associated with bone mineral density among postmenopausal women in Iran. Eur. J. Nutr. 55(2):561-8.

Shivappa, N., Hebert, J.R., Rietzschel, E.R., De Buyzere, M.L., Langlois, M., Debruyne, E., Marcos, A., andHuybrechts, I. 2015b. Associations between dietary inflammatory index and inflammatory markers in the Asklepios Study. Br. J. Nutr. 113: 665-71.

Shivappa, N., Prizment, A.E., Blair, C.K., Jacobs, D.R., Jr., Steck, S.E., andHebert, J.R. 2014a. Dietary inflammatory index and risk of colorectal cancer in the lowa Women's Health Study. Cancer. Epidemiol. Biomarkers. Prev. 23: 2383-92.

Shivappa, N., Steck, S.E., Hurley, T.G., Hussey, J.R., Ma, Y., Ockene, I.S., Tabung, F., andHebert, J.R. 2014b. A population-based dietary inflammatory index predicts levels of C-reactive protein in the Seasonal Variation of Blood Cholesterol Study (SEASONS). Public. Health. Nutr. 17: 1825-33. 
Vahid, F., Zand, H., Nosrat-Mirshekarlou, E., Najafi, R., andHekmatdoost, A. 2015. The role dietary of bioactive compounds on the regulation of histone acetylases and deacetylases: a review. Gene. 562: 815.

Valin, A. and Pablos, J.L. 2015. The Role of the Transcriptional Regulation of Stromal Cells in Chronic Inflammation. Biomolecules. 5: 2723-57.

van Herpen-Broekmans, W.M., Klopping-Ketelaars, I.A., Bots, M.L., Kluft, C., Princen, H., Hendriks, H.F., Tijburg, L.B., van Poppel, G., andKardinaal, A.F. 2004. Serum carotenoids and vitamins in relation to markers of endothelial function and inflammation. Eur. J. Epidemiol. 19: 915-21.

Wang, H., Cao, Q., Ge, J., Liu, C., Ma, Y., Meng, Y., Wang, Y., Zhao, X., Liu, R., Li, C., Wang, Y., Zhong, J., Ju, W., Jenkins, E.C., Brown, W.T., andZhong, N. 2014. LncRNA-regulated infection and inflammation pathways associated with pregnancy loss: genome wide differential expression of IncRNAs in early spontaneous abortion. Am. J. Reprod. Immunol. 72: 359-75.

Wannamethee, S.G., Lowe, G.D., Rumley, A., Bruckdorfer, K.R., andWhincup, P.H. 2006. Associations of vitamin C status, fruit and vegetable intakes, and markers of inflammation and hemostasis. Am. J. Clin. Nutr. 83: 567-74; quiz 726-7.

Wirth, M.D., Burch, J., Shivappa, N., Violanti, J.M., Burchfiel, C.M., Fekedulegn, D., Andrew, M.E., Hartley, T.A., Miller, D.B., Mnatsakanova, A., Charles, L.E., Steck, S.E., Hurley, T.G., Vena, J.E., andHebert, J.R. 2014. Association of a dietary inflammatory index with inflammatory indices and metabolic syndrome among police officers. J. Occup. Environ. Med. 56: 986-9.

Wood, L.G., Shivappa, N., Berthon, B.S., Gibson, P.G., andHebert, J.R. 2015. Dietary inflammatory index is related to asthma risk, lung function and systemic inflammation in asthma. Clin. Exp. Allergy. 45: 17783. 


\begin{tabular}{|c|c|c|c|}
\hline Mean \pm SD or $\mathrm{N}(\%)$ & Cases $(n=67)$ & Controls $(n=68)$ & P-value \\
\hline Age (years) & $31.21 \pm 4.44$ & $30.62 \pm 4.71$ & 0.42 \\
\hline $\begin{array}{l}\text { Body Mass Index (BMI) } \\
\mathrm{kg} / \mathrm{m} 2\end{array}$ & $25.21 \pm 1.70$ & $24.90 \pm 2.12$ & 0.49 \\
\hline $\begin{array}{l}\text { Dietary Inflammatory } \\
\text { Index (DII) }\end{array}$ & $1.51 \pm 0.60$ & $1.22 \pm 0.63$ & $<0.01$ \\
\hline C-reactive protein (mg/L) & $3.14 \pm 1.73$ & $2.77 \pm 1.43$ & 0.18 \\
\hline Interleukin-6 (pg/ml) & $75.75 \pm 38.90$ & $61.00 \pm 31.53$ & 0.02 \\
\hline Education & & & 0.82 \\
\hline High School Diploma & $35(52.2)$ & $39(57.4)$ & \\
\hline Graduate & $25(37.3)$ & $22(32.3)$ & \\
\hline Doctorate level & $7(10.5)$ & $7(10.3)$ & \\
\hline Occupation & & & 0.15 \\
\hline Housekeeper & $39(58.2)$ & $45(66.2)$ & \\
\hline Part time worker & $17(25.4)$ & $19(27.9)$ & \\
\hline Full time worker & $11(16.4)$ & $4(5.9)$ & \\
\hline
\end{tabular}

${ }^{\mathrm{a}}$ ANOVA was used for continuous variables and Chi-square was used for categorical variables. 


\begin{tabular}{|c|c|c|c|}
\hline Mean \pm SD or $N(\%)$ & DII $\leq 1.24(n=34)$ & DII $>1.24(n=34)$ & P-value \\
\hline Age (years) & $31.62 \pm 4.62$ & $29.61 \pm 4.61$ & 0.07 \\
\hline $\begin{array}{l}\text { Body Mass Index (BMI) } \\
\mathrm{kg} / \mathrm{m} 2\end{array}$ & $24.43 \pm 2.00$ & $25.52 \pm 2.01$ & 0.03 \\
\hline Education & & & 0.07 \\
\hline High School Diploma & $15(44.1)$ & $24(70.6)$ & \\
\hline Graduate & $15(44.1)$ & $7(20.6)$ & \\
\hline Doctorate level & $4(11.8)$ & $3(8.8)$ & \\
\hline Occupation & & & 0.58 \\
\hline Housekeeper & $23(67.6)$ & $22(64.7)$ & \\
\hline Part time worker & $10(29.4)$ & $9(26.5)$ & \\
\hline Full time worker & $1(2.9)$ & $3(8.8)$ & \\
\hline
\end{tabular}

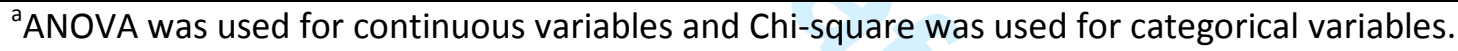




\begin{tabular}{|l|l|l|l|l|}
\hline \multicolumn{2}{|l|}{ Table 3. Beta estimates and confidence intervals for the association between DII and inflammatory markers } \\
\hline & $\begin{array}{l}\text { Beta estimates for } \\
\text { continuous DII }{ }^{a}\end{array}$ & P-value & Beta estimates for continuous DII ${ }^{\mathrm{b}}$ & P-value \\
\hline $\begin{array}{l}\text { C-reactive protein } \\
\left(\mathrm{mg} / \mathrm{I}^{\mathrm{c}}\right.\end{array}$ & $0.08(-0.05,0.22)$ & 0.22 & $0.04(-0.09,0.18)$ & 0.54 \\
\hline $\begin{array}{l}\text { Interleukin-6 } \\
(\mathrm{pg} / \mathrm{ml})^{c}\end{array}$ & $0.14(<0.01,0.28)$ & 0.04 & $0.16(0.02,0.30)$ & 0.03 \\
\hline
\end{tabular}

${ }^{a}$ Age adjusted

${ }^{\mathrm{b}}$ Additionally adjusted for BMI, education, and occupation.

${ }^{\mathrm{C}}$ Log transformed 


\begin{tabular}{|l|l|l|l|l|l|}
\hline \multicolumn{6}{|l|}{ Table 4. Odds ratios and confidence intervals for the association between DII and abortion. } \\
\hline & $\begin{array}{l}\text { Dietary Inflammatory Index (categorical) OR } \\
(95 \% \mathrm{Cl})\end{array}$ & P-Value & $\begin{array}{l}\text { DII(Continuous) } \\
\text { OR (95\% Cl) }\end{array}$ & P-Value \\
\hline DII & DII $\leq 1.24$ & DII>1.24 & & & \\
\hline Age-adjusted & 1 (ref.) & $2.26(1.11,4.60)$ & 0.02 & $2.15(1.22,3.80)$ & $<0.01$ \\
\hline $\begin{array}{l}\text { Multivariable- } \\
\text { adjusted }^{\text {a }}\end{array}$ & 1 (ref.) & $2.12(1.02,4.43)$ & 0.04 & $2.05(1.14,3.70)$ & 0.02 \\
\hline
\end{tabular}

a Adjusted for age, BMI, education, and occupation 